\title{
Test Set of Gaseous Analytes at Hanford Tank Farms
}

\author{
Topical Report
}

January 1997

DISTABUTION OF THIS DOCURENT IS UNLIMTED
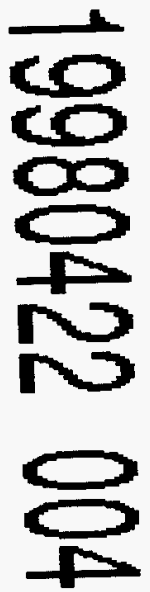

Work Performed Under Contract No.: DE-AR21-95MC32087

For

U.S. Department of Energy

Office of Environmental Management

Office of Technology Development

1000 Independence Avenue

Washington, DC 20585
U.S. Department of Energy

Office of Fossil Energy

Morgantown Energy Technology Center

P.O. Box 880

Morgantown, West Virginia 26507-0880

\section{By}

Electronic Sensors and Systems Division

Northrop Grumman Corporation

Science and Technology Center

1310 Beulah Road

Pittsburgh, Pennsylvania 15235-5098
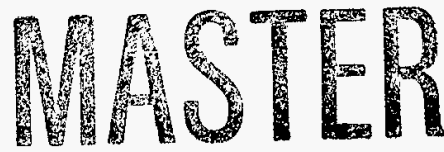


\section{Disclaimer}

This report was prepared as an account of work sponsored by an agency of the United States Government. Neither the United States Government nor any agency thereof, nor any of their employees, makes any warranty, express or implied, or assumes any legal liability or responsibility for the accuracy, completeness, or usefulness of any information, apparatus, product, or process disclosed, or represents that its use would not infringe privately owned rights. Reference herein to any specific commercial product, process, or service by trade name, trademark, manufacturer, or otherwise does not necessarily constitute or imply its endorsement, recommendation, or favoring by the United States Government or any agency thereof. The views and opinions of authors expressed herein do not necessarily state or reflect those of the United States Government or any agency thereof. 


\begin{abstract}
DOE has stored toxic and radioactive waste materials in large underground tanks. When the vapors in the tank headspaces vent to the open atmosphere a potentially dangerous situation can occur for personnel in the area. An open-path atmospheric pollution monitor is being developed to monitor the open air space above these tanks.

In developing this infrared spectra monitor as a safety alert instrument, it is important to know what hazardous gases, called the Analytes of Concern, are most likely to be found in dangerous concentrations. The monitor must also consider other gases which could interfere with measurements of the Analytes of Concern. The total list of gases is called the Test Set Analytes because they form the basis for testing the pollution monitor in future field tests at the DOE Hanford Site.

Prior measurements in 54 tank headspaces have detected 102 toxic air pollutants (TAPs) and over 1000 other analytes. The hazardous Analytes are ranked herein by a "Hazardous Atmosphere Rating" which combines their measured concentration, their density relative to air, and the concentration at which they become dangerous. The top 20 toxic air pollutants, as ranked by the Hazardous Atmosphere Rating, and the top 20 other analytes, in terms of measured concentrations, are analyzed for possible inclusion in the Test Set Analytes. Of these 40 gases, 20 are selected.

To these 20 gases are added the 6 omnipresent atmospheric gases with the highest concentrations, since their spectra could interfere with measurements of the other spectra. The 26 Test Set Analytes are divided into a Primary Set and a Secondary Set. The Primary Set, gases which must be detectable by the monitor, includes the 6 atmospheric gases and the 6 hazardous gases which have been measured at dangerous concentrations. The Secondary Set gases need not be monitored at this time.

The infrared spectra, barring atmospheric interferences, indicates that:
\end{abstract}

- The pollution monitor will detect all 26 Test Set Analytes by thermal emission

- The pollution monitor will detect 15 Test Set Analytes by laser absorption 


\section{TABLE OF CONTENTS}

ABSTRACT

1. INTRODUCTION

2. TANK HEADSPACE MEASUREMENTS 3

2.1 Ecology-Affecting Toxic Air Pollutants 3

2.2 Health-Affecting Toxic Air Pollutants 4

2.3 Other Tank Vapors 6

2.4 Atmospheric Gases 6

3. SELECTION OF ANALYTE TEST SET 8

4. DANGEROUS ANALYTE PROPERTIES 10

4.1 Fire and Explosive Hazards 10

4.2 Health Hazards 11

4.3 Hazard Ratings $\quad 12$

5. PRIMARY AND SECONDARY TEST SETS 14

5.1 Test Sets 14

5.2 Infrared Spectra 15

6. REFERENCES 17 


\section{INTRODUCTION}

In the process of manufacturing nuclear reactor fuel at the DOE Hanford Reservation and Savannah River sites, large amounts of toxic and radioactive waste materials have been generated and stored in hundreds of large underground tanks such as the one shown in Figure 1. These waste materials include the solvents used in the various recovery and decontamination processes, radiation-induced decay products, and numerous chemical reaction products from the stored chemicals. The tanks are grouped together into a few areas called "tank farms".

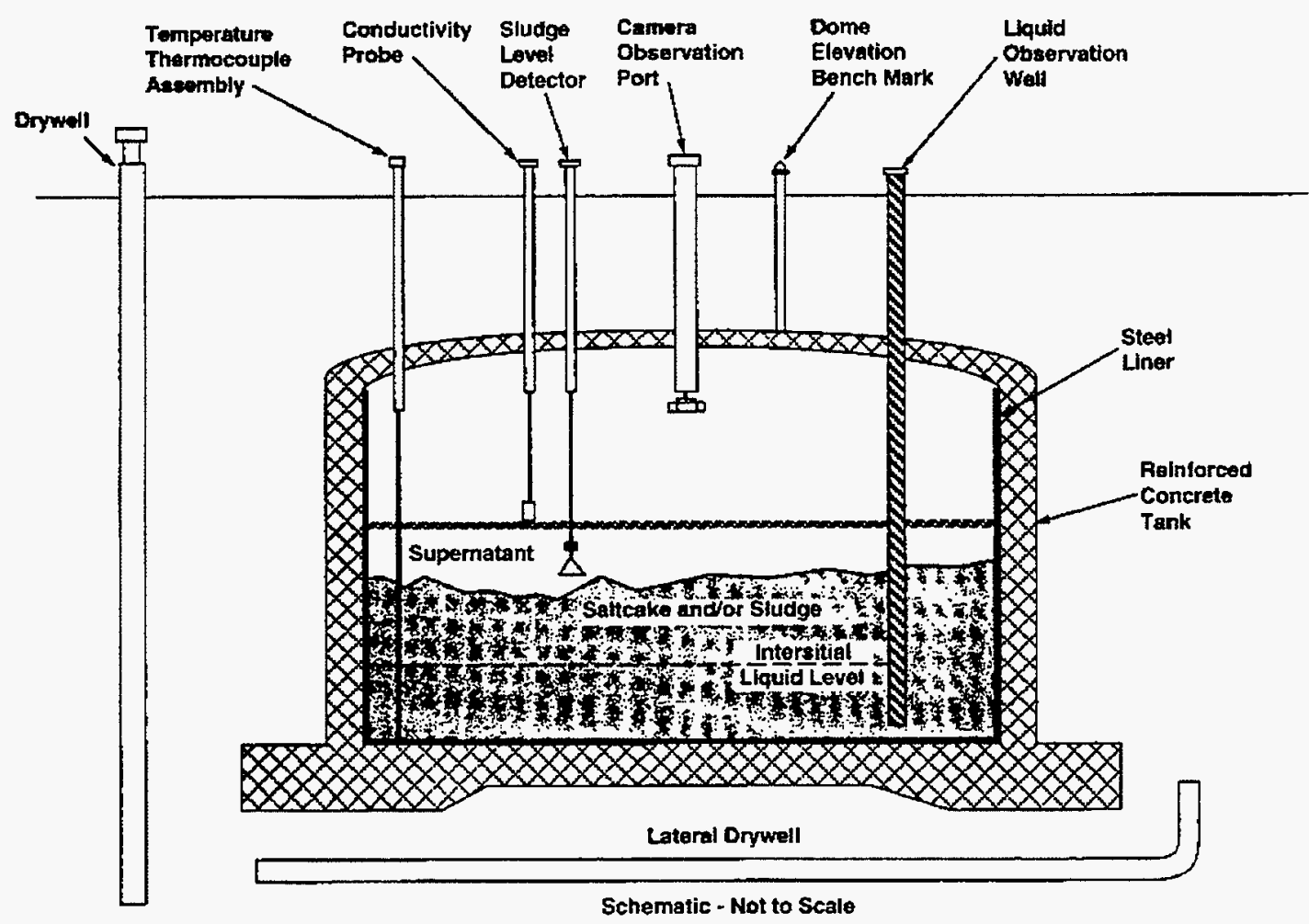

Figure 1 -- A typical underground double-shell waste storage tank is very large and contains toxic vapors which can vent to the open atmosphere.

Since the mid-1940s employees working in the vicinity of these tanks have occasionally reported health problems such as headaches, burning sensations in the nose and throat, nausea, and impaired pulmonary function. These problems may have arisen from vapors released from the tanks. The open-path atmospheric pollution monitor, called the Thermal Emission, Laser Absorption (TELA) Monitor, being developed under this DOE contract is to monitor the open air above these tank farms whenever personnel are present and to sound an alarm whenever potentially harmful gases approach dangerous levels of concentrations. 
In developing this monitor for personnel safety it is important to know the specific harmful gases which must be monitored. Several lists of candidates have been developed from measurements in the vapor headspaces of several tanks. However, since no monitor can efficiently and effectively detect all of the candidate gases - there are simply too many - and since all of the candidate gases are not equally dangerous, a focused list of analytes is determined from the most comprehensive list of gases measured in the tank headspaces. To keep the pollution monitor development effort within reasonable limits the list must not be too large but must include gases which exist in relatively high concentrations in the Hanford tank headspaces and in the Hanford aboveground air.

It is this selected set of analytes, the "Analyte Test Set", that will be addressed during the performance of this contract. This list results from a selection process explained herein which addresses relative risk of vapors known to be in the headspaces. To this list of hazardous gases are added those gases whose concentrations are sufficiently high that their spectra may interfere with the measurements of the hazardous gas spectra. The open-path atmospheric monitor is being designed under this contract to detect the hazardous analytes at concentration levels below those which would adversely affect the health of personnel in the area.

Chapter 2 examines gas measurements in the Hanford tank headspaces. In particular, the twenty toxic air pollutants (TAPs) with the highest measured concentrations and the twenty TAPs with the highest danger rankings are listed. The chapter concludes with twenty additional gases which have the highest mass densities and with sixteen naturally occurring atmospheric gases. Each hazardous gas is rated according to the danger it presents.

From this information an Analytes Test Set of twenty-six gases is determined in Chapter 3. Chapter 4 details the hazards which the selected gases present to exposed personnel. These hazards include fire \& explosion dangers from sixteen Analytes plus health effects from twenty-two Analytes.

Chapter 5 divides the twenty-six Analytes into a Primary Test Set and a Secondary Test Set. The Primary Test Set of twelve Analytes must be monitored whereas the Secondary Test Set of fourteen Analytes need not be monitored at this time. It is also shown that fifteen Analytes can likely be detected with the active lidar (laser absorption) and all twenty-six gases can likely be detected with the passive filter (thermal emission) operation of the TELA Monitor. 


\section{TANK HEADSPACE MEASUREMENTS}

At least four Analytes of Concern lists have been compiled for the Hanford tank headspaces. ${ }^{1-4}$ These four sources identified 47 hazardous vapors which have been detected in at least two tanks and 15 more which have detected in only one tank. From these lists we compiled an early version of an Analytes of Concern Test List which we detailed in a DOE Topical Report ${ }^{5}$ on this contract and included as part of a paper ${ }^{6}$ delivered at the 1996 Instrument Society of America Analysis Division Symposium.

In a visit to Hanford in June 1996, Jim Huckaby ${ }^{7}$ provided two comprehensive lists of analytes which have had their concentrations measured in the Hanford tank headspaces. The first list includes 102 toxic air pollutants and the second list includes 1068 "Tank Chemicals". The lists have a few duplications. The TAP list is composed of particularly hazardous vapors. These two lists were used for the analysis in this report.

\subsection{Ecology-Affecting Toxic Air Pollutants}

The Huckaby list of toxic air pollutants includes 102 vapors rated not by their hazardous properties but by their measured concentration relative to their ASL value. This value is the Acceptable Source Impact Limit which, in a peculiar line of reasoning by the Washington State Department of Ecology, is based on environmental effects - not on health or danger effects. In particular, the ASIL is that concentration which does not significantly impact the public environment. For example, if the concentration of carbon tetrachloride is $1.07 \times 10^{-5} \mathrm{ppm}$ in the general air surrounding the Hanford Site, then any carbon tetrachloride released by the Hanford Site cannot significantly change this concentration. In particular, the limit applies to a 24 hour average at outdoor campgrounds and to annual averages at residential areas. Four aspects of this limit are:

- ASIL values are generally extremely low and therefore very hard to measure

- ASIL values are measured where they impact the public

- ASIl values have little connection to the hazard they present to the public

- ASIL values have no connection to the hazard presented to Hanford personnel

The second aspect means that TAP concentrations must be below ASIL values where they impact the public, e.g., on public roads or farms nearest the Hanford Site. The last two aspects are evident when ASIL concentrations are compared to hazardous concentrations.

Table 1 lists the twenty TAPs which have been measured in a tank headspace with the highest concentrations relative to their ASL values. The Chemical Abstract Service (CAS) Registry number is given for each analyte. The third column gives the number of tanks in which the analyte has been measured. The average and maximum concentrations measured in the tanks are in the fourth and fifth columns. The last two columns give the ASIL value and the ratio of the maximum measured concentration relative to the ASIL concentration, respectively. 
Table 1 - Hanford tank TAPs with the highest concentrations (relative to ASIL values).

\begin{tabular}{|l|r|r|c|c|c|c|}
\hline \multicolumn{1}{|c|}{ TAP } & \multicolumn{1}{c|}{ CAS \# } & $\begin{array}{c}\text { No. of } \\
\text { Tanks }\end{array}$ & $\begin{array}{c}\text { Average } \\
\text { ppm }\end{array}$ & $\begin{array}{c}\text { Max. } \\
\text { ppm }\end{array}$ & $\begin{array}{c}\text { ASIL } \\
\text { ppm }\end{array}$ & $\begin{array}{c}\text { Max. / } \\
\text { ASIL }\end{array}$ \\
\hline N-Nitrosodimethylamine & $62-75-9$ & 12 & $3.70 \mathrm{E}-2$ & $8.96 \mathrm{E}-2$ & $2.35 \mathrm{E}-8$ & $3.82 \mathrm{E}+6$ \\
Butadiene & $106-99-0$ & 12 & $5.36 \mathrm{E}-2$ & $1.90 \mathrm{E}-1$ & $1.64 \mathrm{E}-6$ & $1.16 \mathrm{E}+5$ \\
Carbon tetrachloride & $56-23-5$ & 8 & $5.16 \mathrm{E}-2$ & $3.47 \mathrm{E}-1$ & $1.07 \mathrm{E}-5$ & $3.25 \mathrm{E}+4$ \\
Benzene & $71-43-2$ & 46 & $3.59 \mathrm{E}-2$ & $6.93 \mathrm{E}-1$ & $3.77 \mathrm{E}-5$ & $1.84 \mathrm{E}+4$ \\
Methylene chloride & $75-09-2$ & 36 & $1.20 \mathrm{E}-1$ & $1.88 \mathrm{E}+0$ & $1.61 \mathrm{E}-4$ & $1.17 \mathrm{E}+4$ \\
Ammonia & $7664-41-7$ & 54 & $2.23 \mathrm{E}+2$ & $1.14 \mathrm{E}+3$ & $1.44 \mathrm{E}-1$ & $7.93 \mathrm{E}+3$ \\
Tributyl phosphate & $126-73-8$ & 24 & $2.96 \mathrm{E}-1$ & $5.22 \mathrm{E}+0$ & $6.72 \mathrm{E}-4$ & $7.77 \mathrm{E}+3$ \\
Ethylene oxide & $75-21-8$ & 1 & $2.89 \mathrm{E}-2$ & $2.89 \mathrm{E}-2$ & $5.57 \mathrm{E}-6$ & $5.19 \mathrm{E}+3$ \\
Polychlorinated Biphenyls & $1336-36-3$ & 5 & $4.50 \mathrm{E}-6$ & $1.59 \mathrm{E}-3$ & $3.77 \mathrm{E}-7$ & $4.22 \mathrm{E}+3$ \\
Ethylene dibromide & $106-93-4$ & 1 & $4.50 \mathrm{E}-6$ & $2.39 \mathrm{E}-3$ & $5.87 \mathrm{E}-7$ & $4.07 \mathrm{E}+3$ \\
Chloroform & $67-66-3$ & 8 & $4.83 \mathrm{E}-3$ & $1.68 \mathrm{E}-2$ & $8.84 \mathrm{E}-6$ & $1.90 \mathrm{E}+3$ \\
Dioxane & $123-91-1$ & 4 & $9.47 \mathrm{E}-3$ & $1.68 \mathrm{E}-2$ & $8.89 \mathrm{E}-6$ & $1.89 \mathrm{E}+3$ \\
Acetaldehyde & $75-07-0$ & 16 & $9.06 \mathrm{E}-2$ & $3.76 \mathrm{E}-1$ & $2.51 \mathrm{E}-4$ & $1.50 \mathrm{E}+3$ \\
Cyanide & $57-12-5$ & 49 & $5.78 \mathrm{E}-1$ & $1.40 \mathrm{E}+1$ & $1.60 \mathrm{E}-2$ & $8.73 \mathrm{E}+2$ \\
Perchloroethylene & $127-18-4$ & 24 & $9.74 \mathrm{E}-3$ & $1.14 \mathrm{E}-1$ & $1.62 \mathrm{E}-4$ & $7.02 \mathrm{E}+2$ \\
Biphenyl & $92-52-4$ & 3 & $1.93 \mathrm{E}-4$ & $4.38 \mathrm{E}-1$ & $6.83 \mathrm{E}-4$ & $6.41 \mathrm{E}+2$ \\
Acrylonitrile & $107-13-1$ & 1 & $2.81 \mathrm{E}-3$ & $2.81 \mathrm{E}-3$ & $6.92 \mathrm{E}-6$ & $4.06 \mathrm{E}+2$ \\
n-Butyl alcohol & $71-36-3$ & 52 & $2.79 \mathrm{E}+0$ & $6.29 \mathrm{E}+1$ & $1.65 \mathrm{E}-1$ & $3.81 \mathrm{E}+2$ \\
2,6-Di-tert-butyl-p-cresol & $128-37-0$ & 2 & $3.27 \mathrm{E}-1$ & $6.52 \mathrm{E}-1$ & $3.66 \mathrm{E}-3$ & $1.78 \mathrm{E}+2$ \\
Acetronitrile & $75-05-8$ & 49 & $5.71 \mathrm{E}-1$ & $1.44 \mathrm{E}+1$ & $1.31 \mathrm{E}-1$ & $1.10 \mathrm{E}+2$ \\
\hline
\end{tabular}

The entries in Table 1 show that 54 tank headspaces have been sampled and that most of the analytes occur in many tanks. Furthermore, the ASL values have a wide variation, from the extremely low value of $2.35 \times 10^{-8} \mathrm{ppm}$ for $\mathrm{n}$-nitrosodimethylamine to $1.31 \times 10^{-1} \mathrm{ppm}$ for acetronitrile. With these low values, it is not surprising that the maximum concentrations measured in the tank headspaces exceed the ASIL values.

The numerical entries in Table 1, and in all other tables in this report, are given to three significant figures or less. Chemical names are the Occupational Safety and Health Administration (OSHA) names when known. When the OSHA name is not known, the preferred name according to Howard and Neal ${ }^{8}$ is given. Molecular formulas are ordered by the Hill system ${ }^{8}$ (order of symbols is carbon, hydrogen, and then alphabetical by element).

\subsection{Health-Affecting Toxic Air Pollutants}

Open air situations are primarily concerned with health effects. A measure of the danger from a chemical is given by the Threshold Limit Value-Time-Weighted Average (TWA) in parts per million by volume at $25^{\circ} \mathrm{C}$ and 760 Torr as specified by the American Conference of Governmental Industrial Hygienists (ACGIH). ${ }^{9}$ Nearly all workers may be repeatedly exposed to the TWA value, day after day, for a normal 8-hour workday and a 40-hour workweek, without adverse effects.

To determine a meaningful and quantifiable hazardous rating for each chemical vapor, we note that the higher the vapor pressure, the more likely the chemical will be present at high concentrations in the air. Furthermore, the higher the density the more likely the chemical will pool, or collect, in low places and the less likely it will be 
dispersed by wind. A particularly dangerous chemical would have both a high vapor pressure (expressed in ppm) and a high density (relative to dry air which has an average mass of $28.96 \mathrm{amu}$ ), as well as a low TWA value (in ppm) resulting from deleterious health effects. Based on these relationships, we define an unitless "Hazardous Atmosphere Rating (HAR)" for each chemical as:

$$
H A R=(\text { Concentration }) *(\text { Relative Density }) / T W A
$$

Note that gases with $H A R$ values greater than 1.0 are potentially dangerous and that gases with $H A R$ values less than 1.0 are not normally dangerous.

This rating equation is ideally suited to the open atmosphere in which there is no wind and the chemical vapor is in equilibrium with its liquid source. However, to be applicable to the Hanford tanks, the concentration in Eq. 1 should be the measured concentration in the tank since that will be the concentration ${ }^{*}$ in any vapor release from the tank. In fact, whenever the vapor concentration is known from measurements, that is the value which should be used in Eq. 1.

Table 2 lists the twenty TAPs with the highest HAR values. The TWA values are predominately from reference 9 with a few from the R. J. Lewis Desk Reference ${ }^{10}$. Maximum concentrations measured in the tanks are used because the HAR values then represent the greatest danger from the tanks. Of the twenty TAPs listed, twelve also appear in Table 1. The largest to smallest $H A R$ values differ by a factor of 3000 , indicating a large variation in the potential danger these chemicals present.

Table 2 - Hanford tank TAPs with the highest $H A R$ values.

\begin{tabular}{|l|r|r|c|c|c|c|}
\hline \multicolumn{1}{|c|}{ TAP } & \multicolumn{1}{c|}{ CAS \# } & $\begin{array}{c}\text { No. of } \\
\text { Tanks }\end{array}$ & $\begin{array}{c}\text { Average } \\
\text { ppm }\end{array}$ & $\begin{array}{c}\text { Max. } \\
\text { ppm }\end{array}$ & $\begin{array}{c}\text { TWA } \\
\text { ppm }\end{array}$ & $\begin{array}{c}\text { Max. } \\
\boldsymbol{H A R}\end{array}$ \\
\hline Tributyl phosphate & $126-73-8$ & 24 & $2.96 \mathrm{E}-1$ & $5.22 \mathrm{E}+0$ & 0.2 & $\mathbf{2 4 0 . 0 0}$ \\
Polychlorinated Biphenyls & $1336-36-3$ & 5 & $4.50 \mathrm{E}-6$ & $1.59 \mathrm{E}-3$ & $8 \mathrm{E}-5$ & $\mathbf{1 9 1 . 0 0}$ \\
Ammonia & $7664-41-7$ & 54 & $2.23 \mathrm{E}+2$ & $1.14 \mathrm{E}+3$ & 25 & $\mathbf{2 6 . 8 0}$ \\
Biphenyl & $92-52-4$ & 3 & $1.93 \mathrm{E}-4$ & $4.38 \mathrm{E}-1$ & 0.2 & $\mathbf{1 1 . 7 0}$ \\
2,6-Di-tert-butyl-p-cresol & $128-37-0$ & 2 & $3.27 \mathrm{E}-1$ & $6.52 \mathrm{E}-1$ & 1 & $\mathbf{4 . 9 6}$ \\
n-Butyl alcohol & $71-36-3$ & 52 & $2.79 \mathrm{E}+0$ & $6.29 \mathrm{E}+1$ & 50 & $\mathbf{3 . 2 2}$ \\
Cyanide & $57-12-5$ & 49 & $5.78 \mathrm{E}-1$ & $1.40 \mathrm{E}+1$ & 5 & $\mathbf{2 . 5 2}$ \\
Acetonitrile & $75-05-8$ & 49 & $5.71 \mathrm{E}-1$ & $1.44 \mathrm{E}+1$ & 40 & 0.51 \\
2-Hexanone & $591-78-6$ & 43 & $3.63 \mathrm{E}-2$ & $6.44 \mathrm{E}-1$ & 5 & 0.44 \\
Carbon tetrachloride & $56-23-5$ & 8 & $5.16 \mathrm{E}-2$ & $3.47 \mathrm{E}-1$ & 5 & 0.37 \\
Trimethylamine & $75-50-3$ & 1 & $6.88 \mathrm{E}-1$ & $6.88 \mathrm{E}-1$ & 10 & 0.28 \\
Carbon disulfide & $75-15-0$ & 2 & $4.60 \mathrm{E}-1$ & $8.65 \mathrm{E}-1$ & 10 & 0.23 \\
Diphenylamine & $122-39-4$ & 7 & $6.41 \mathrm{E}-3$ & $3.31 \mathrm{E}-2$ & 1 & 0.19 \\
Benzene & $71-43-2$ & 46 & $3.59 \mathrm{E}-2$ & $6.93 \mathrm{E}-1$ & 10 & 0.19 \\
1,3-Butadiene & $106-99-0$ & 12 & $5.36 \mathrm{E}-2$ & $1.90 \mathrm{E}-1$ & 2 & 0.18 \\
Methyl ethyl ketone & $78-93-3$ & 40 & $4.83 \mathrm{E}-1$ & $1.32 \mathrm{E}+1$ & 200 & 0.16 \\
Phenyl ether & $101-84-8$ & 2 & $1.32 \mathrm{E}-2$ & $2.60 \mathrm{E}-2$ & 1 & 0.15 \\
Methylene chloride & $75-09-2$ & 36 & $1.20 \mathrm{E}-1$ & $1.88 \mathrm{E}+0$ & 50 & 0.11 \\
Methylacrylonitrile & $126-98-7$ & 1 & $4.02 \mathrm{E}-2$ & $4.02 \mathrm{E}-2$ & 1 & 0.09 \\
Ethyl acetate & $141-78-6$ & 3 & $3.70 \mathrm{E}+0$ & $1.09 \mathrm{E}+1$ & 400 & 0.08 \\
\hline
\end{tabular}

*At least until it is dispersed by convection, diffusion, or wind 


\subsection{Other Tank Vapors}

A comprehensive survey of tank vapors has detected 1068 chemicals. ${ }^{7}$ The twenty vapors with the highest mass densities, excluding TAPs listed in Tables 1 and 2, are listed in Table 3. This list includes most of the normally present atmospheric gases. The variation in concentrations is very large.

Table 3 - Additional Hanford tank vapors with the highest mass densities.

\begin{tabular}{|l|r|r|r|r|r|r|}
\hline \multicolumn{1}{|c|}{ Gas } & \multicolumn{1}{|c|}{ CAS \# } & $\begin{array}{r}\text { No. of } \\
\text { Tanks }\end{array}$ & $\begin{array}{c}\text { Min. } \\
\text { ppm }\end{array}$ & $\begin{array}{c}\text { Average } \\
\text { ppm }\end{array}$ & $\begin{array}{r}\text { Max. } \\
\text { ppm }\end{array}$ & $\begin{array}{r}\text { Max. } \\
\mathbf{m g} / \mathbf{m}^{3}\end{array}$ \\
\hline Carbon dioxide & $124-38-9$ & 49 & 0.368 & 211.00 & 1560.0 & 2800.00 \\
Nitrous oxide & $10024-97-2$ & 50 & 3.280 & 234.00 & 958.0 & 1720.00 \\
Butyraldehyde & $123-72-8$ & 44 & 0.000 & 1.46 & 53.3 & 157.00 \\
Hydrogen & $1333-74-0$ & 38 & 10.500 & 247.00 & 827.0 & 68.20 \\
Tridecane & $629-50-5$ & 51 & 0.000 & 0.31 & 4.4 & 32.80 \\
Acetone & $67-64-1$ & 61 & 0.008 & 0.94 & 10.8 & 25.70 \\
Dodecane & $112-40-3$ & 50 & 0.000 & 0.23 & 3.5 & 24.10 \\
Carbon monoxide & $630-08-0$ & 14 & 0.110 & 2.37 & 17.0 & 19.40 \\
3-Butene-1-ol & $627-27-0$ & 2 & 0.026 & 3.12 & 6.2 & 18.20 \\
Trichlorofluoromethane & $75-69-4$ & 59 & 0.001 & 0.21 & 3.2 & 17.90 \\
2-methyl-Pentane & $107-83-5$ & 15 & 0.001 & 0.54 & 4.3 & 15.10 \\
Tetradecane & $629-59-4$ & 41 & 0.000 & 0.17 & 1.8 & 14.70 \\
7-Methyl-tridecane & $26730-14-3$ & 14 & 0.001 & 0.19 & 1.5 & 11.80 \\
Undecane & $1120-21-4$ & 46 & 0.000 & 0.11 & 1.8 & 11.30 \\
4,6-Dimethyl-dodecane & $6114-72-8$ & 7 & 0.003 & 0.38 & 1.2 & 9.60 \\
Ethanol & $64-17-5$ & 43 & 0.000 & 0.47 & 5.0 & 9.44 \\
Hexane & $110-54-3$ & 50 & 0.000 & 0.15 & 2.5 & 8.66 \\
Methane & $74-82-8$ & 12 & 0.073 & 3.87 & 13.1 & 8.59 \\
Furan, tetrahydro- & $109-99-9$ & 38 & 0.000 & 0.13 & 2.0 & 5.83 \\
decahydro-2-methyl-Napthalene & $2958-76-1$ & 12 & 0.001 & 0.17 & 1.4 & 8.31 \\
\hline
\end{tabular}

\subsection{Atmospheric Gases}

In measuring pollutant vapors in the open atmosphere, all monitors must contend with the omnipresent atmospheric gases which can significantly interfere with the measurement of pollutant concentrations or even their detection. Table 4 lists the atmospheric gases with nominal concentrations above $1 \mathrm{ppb}$. The gases fall naturally into two separate categories: (Category 1) atomic and homonuclear diatomic molecules, and (Category 2) all other molecules. Atmospheric gases in the first category are given in the left side of the table ${ }^{11}$ and gases in the second category are given in the right side. This distinction is important because the Category 1 gases are so spatially symmetric that they do not have a permanent electric dipole. Without a permanent electric dipole, infrared transitions are very weak or nonexistent. Thus, Category 1 gases can be neglected.

Category 2 gases include all molecules of interest. The concentrations given here are from the U.S. Standard Model Atmosphere, $1976,{ }^{12}$ as presented by Anderson et al. ${ }^{13}$ for sea level conditions. As such, the concentrations given should be considered as nominal, or representative. 
Table 4 - Category 1 (very weak infrared spectra) and Category 2 (extensive infrared spectra) atmospheric gases.

\begin{tabular}{|l|c|r|l|c|r|r|}
\hline \multicolumn{3}{|c|}{ Category 1 Gases } & \multicolumn{4}{c|}{ Category 2 Gases } \\
\hline Name & Formula & $\begin{array}{c}\text { Nominal } \\
\text { ppb }\end{array}$ & Name & Formula & CAS \# & $\begin{array}{c}\text { Nominal } \\
\text { ppb }\end{array}$ \\
\hline Nitrogen & $\mathrm{N}_{2}$ & 780840000 & Water & $\mathrm{H}_{2} \mathrm{O}$ & $7732-18-5$ & 7750000 \\
Oxygen & $\mathrm{O}_{2}$ & 209480000 & Carbon dioxide & $\mathrm{CO}_{2}$ & $124-38-9$ & 330000 \\
Argon & $\mathrm{Ar}$ & 9340000 & Methane & $\mathrm{CH}_{4}$ & $74-82-8$ & 1700 \\
Neon & $\mathrm{Ne}$ & 18200 & Nitrous oxide & $\mathrm{N}_{2} \mathrm{O}$ & $10024-97-2$ & 320 \\
Helium & $\mathrm{He}$ & 5200 & Carbon monoxide & $\mathrm{CO}$ & $630-08-0$ & 150 \\
Krypton & $\mathrm{Kr}$ & 1100 & Ozone & $\mathrm{O}_{3}$ & $10028-15-6$ & 27 \\
Hydrogen & $\mathrm{H}_{2}$ & 500 & Formaldehyde & $\mathrm{CH}_{2} \mathrm{O}$ & $50-00-0$ & 2 \\
Xenon & $\mathrm{Xe}$ & 100 & Hydrogen chloride & $\mathrm{HCl}$ & $7647-01-0$ & 1 \\
\hline
\end{tabular}




\section{SELECTION OF ANALYTE TEST SET}

It would be too expensive and time-consuming to test the TELA Monitor by measuring all the gases in the above tables. In down-sizing this list of gases, two choices are obvious: (1) eliminate all Category 1 gases since they do not effectively absorb in the infrared and (2) eliminate all gases which were measured in only one or two tanks since they are not very common.

Conversely, the TAP gases with high HAR values are the most important ones to include. From Table 2, there is a significant break in $H A R$ values between cyanide and acetonitrile. We therefore include the seven TAPs from tributyl phosphate to cyanide, inclusive. We then add acetonitrile, methyl ethyl ketone, and ethyl acetate because their concentrations are sufficiently high that their spectra could interfere with those of the selected seven TAPs. To these ten we arbitrarily add those TAPs with concentrations over 10,000 times their ASIL values, i.e., the first five TAPs in Table 1. These five are the vapors of most concern for ecological reasons.

To this list of TAPs we add other gases which are not really of much interest except that their concentrations are sufficiently high that they could significantly interfere with the measurement of TAP concentrations. From Table 3 we add the eleven Category 2 gases with maximum concentrations above 3 ppm and from Table 4 we add the six Category 2 gases with nominal concentrations above $5 \mathrm{ppb}$.

Duplications reduce this list of thirty-two gases to twenty-eight gases but we must also eliminate mixtures since each component of the mixture has its own infrared spectra and must therefore be treated as a separate gas. Two mixtures are included in the above tables: polychlorinated biphenyls and cyanide. Both items, as reported in the Hanford tank headspace measurements, are really mixtures. Until their actual compositions are known, they cannot be included. However, both items include very dangerous vapors which should be included as Analytes of Concern once their compositions are known.

The final Analyte Test Set, or List, of twenty-six gases is given in Table 5. TWA values have not been determined for the last six analytes in Table 5, but all, excepting water, are known to be dangerous in certain concentrations. Their specific effects are given in the next chapter. Note that maximum HAR values were used to select the Test Set Analytes because they represent the highest danger which might be encountered. However, average HAR values are used to rank the Test Set Analytes because they represent the most probable danger which might be encountered.

On the average, only three Analytes occur in dangerous concentrations (HAR > 1.0): tributyl phosphate, ammonia, and 2,6-Di-tert-butyl-p-cresol. When maximum concentration measurements are considered (see Table 2), five Analytes occur in dangerous concentrations: the latter three gases plus biphenyl and n-butyl alcohol. 
Table 5 - Analyte Test Set for TELA Atmospheric Pollution Monitor. Analytes are ranked according to their average HAR value.

\begin{tabular}{|c|c|c|c|c|c|c|}
\hline Analyte & Formula & $\begin{array}{c}\text { Mass } \\
\text { amu } \\
\end{array}$ & $\begin{array}{l}\text { Relative } \\
\text { Density } \\
\end{array}$ & $\begin{array}{c}\text { Average } \\
\text { ppm }\end{array}$ & $\begin{array}{l}T W A \\
\text { ppm }\end{array}$ & $\begin{array}{c}\text { Average } \\
\text { HAR } \\
\end{array}$ \\
\hline Tributyl phosphate & $\mathrm{C}_{12} \mathrm{H}_{27} \mathrm{O}_{4} \mathrm{P}$ & 266.36 & 9.20 & $2.96 \mathrm{E}-1$ & 0.2 & 13.600 \\
\hline Ammonia & $\mathrm{H}_{3} \mathrm{~N}$ & 17.04 & 0.59 & $2.23 \mathrm{E}+2$ & 25 & 5.250 \\
\hline 2,6-Di-tert-butyl-p-cresol & $\mathrm{C}_{15} \mathrm{H}_{24} \mathrm{O}$ & 220.39 & 7.61 & 3.27E-1 & 1 & 2.490 \\
\hline Ozone & $\mathrm{O}_{3}$ & 48.00 & 1.66 & $2.70 \mathrm{E}-2$ & 0.1 & 0.447 \\
\hline n-Butyl alcohol & $\mathrm{C}_{4} \mathrm{H}_{10} \mathrm{O}$ & 74.14 & 2.56 & $2.79 E+0$ & 50 & 0.143 \\
\hline Carbon dioxide & $\mathrm{CO}_{2}$ & 44.01 & 1.52 & $3.30 \mathrm{E}+2$ & 5000 & 0.100 \\
\hline Carbon tetrachloride & $\mathrm{CCl}_{4}$ & 153.81 & 5.31 & $5.16 \mathrm{E}-2$ & 5 & 0.055 \\
\hline Butadiene & $\mathrm{C}_{4} \mathrm{H}_{6}$ & 54.10 & 1.87 & $5.36 \mathrm{E}-2$ & 2 & 0.050 \\
\hline Ethyl acetate & $\mathrm{C}_{4} \mathrm{H}_{8} \mathrm{O}_{2}$ & 88.12 & 3.04 & $3.70 \mathrm{E}+0$ & 400 & 0.028 \\
\hline Acetonitrile & $\mathrm{C}_{2} \mathrm{H}_{3} \mathrm{~N}$ & 41.06 & 1.42 & $5.71 \mathrm{E}-1$ & 40 & 0.020 \\
\hline Nitrous oxide & $\mathrm{N}_{2} \mathrm{O}$ & 44.02 & 1.52 & $3.20 \mathrm{E}-1$ & 50 & 0.010 \\
\hline Benzene & $\mathrm{C}_{6} \mathrm{H}_{6}$ & 78.12 & 2.70 & $3.59 \mathrm{E}-2$ & 10 & 0.010 \\
\hline Methylene chloride & $\mathrm{CH}_{2} \mathrm{Cl}_{2}$ & 84.93 & 2.93 & $1.20 \mathrm{E}-1$ & 50 & 0.007 \\
\hline Carbon monoxide & $\mathrm{CO}$ & 28.01 & 0.97 & $1.50 \mathrm{E}-1$ & 25 & 0.006 \\
\hline Methyl ethyl ketone & $\mathrm{C}_{4} \mathrm{H}_{8} \mathrm{O}$ & 72.12 & 2.49 & $4.83 \mathrm{E}-1$ & 200 & 0.006 \\
\hline Biphenyl & $\mathrm{C}_{12} \mathrm{H}_{10}$ & 155.22 & 5.32 & $1.93 \mathrm{E}-4$ & 0.2 & 0.005 \\
\hline Acetone & $\mathrm{C}_{3} \mathrm{H}_{6} \mathrm{O}$ & 58.09 & 2.01 & $9.40 \mathrm{E}-1$ & 750 & 0.003 \\
\hline 2-methyl-Pentane & $\mathrm{C}_{6} \mathrm{H}_{14}$ & 86.20 & 2.98 & $5.35 \mathrm{E}-1$ & 500 & 0.003 \\
\hline Trichlorofluoromethane & $\mathrm{CCl}_{3} \mathrm{~F}$ & 137.36 & 4.47 & $2.06 \mathrm{E}-1$ & 1000 & 0.001 \\
\hline Ethanol & $\mathrm{C}_{2} \mathrm{H}_{6} \mathrm{O}$ & 46,98 & 1.59 & $4.69 \mathrm{~F}-1$ & 1000 & 0.001 \\
\hline Water & $\mathrm{H}_{2} \mathrm{O}$ & 18.02 & 0.62 & $7.75 E+3$ & $-\cdots$ & --- \\
\hline Methane & $\mathrm{CH}_{4}$ & 16.05 & 0.55 & $1.70 E+0$ & --- & --- \\
\hline Butyraldehyde & $\mathrm{C}_{4} \mathrm{H}_{8} \mathrm{O}$ & 72.12 & 2.49 & $1.46 \mathrm{E}+0$ & -- & --- \\
\hline Tridecane & $\mathrm{C}_{13} \mathrm{H}_{28}$ & 184.41 & 6.37 & $3.10 \mathrm{E}-1$ & -- & --- \\
\hline Dodecane & $\mathrm{C}_{12} \mathrm{H}_{26}$ & 170.38 & 5.88 & $2.26 \mathrm{E}-1$ & --- & --- \\
\hline $\mathrm{N}$-Nitrosodimethylamine & $\mathrm{C}_{6} \mathrm{H}_{6} \mathrm{~N}_{2} \mathrm{O}$ & 74.10 & 2.56 & $3.70 \mathrm{E}-2$ & -- & $\ldots$ \\
\hline
\end{tabular}




\section{DANGEROUS ANALYTE PROPERTIES}

Now that we have the Test Set Analytes, it is useful to briefly describe the dangerous properties of the Analytes. In particular: (1) their propensity to start or enhance fires, (2) their potential to explode, and (3) their toxicity properties. Various hazard ratings, based on these properties, are given for all the Analytes.

\subsection{Fire and Explosive Hazards}

The fire hazard for open air situations is determined by the flash point (FP) which is the temperature to which a material must be heated before the vapors will ignite by a free flame in the presence of air. The known flash points ${ }^{10}$ for all the Test Set Analytes are given ${ }^{*}$ in Table 6, as is the U.S. Department of Transportation (DOT) Code: ${ }^{14}$

$\begin{array}{ll}\text { Extremely Flammable }(E F) & F P<70^{\circ} \mathrm{F} \\ \text { Flammable }(F) & 70^{\circ} \mathrm{F} \leq F P \leq 100^{\circ} \mathrm{F} \\ \text { Combustible }(C) & 100^{\circ} \mathrm{F} \leq F P \leq 200^{\circ} \mathrm{F} \\ \text { Nonflammable (NF) } & 200^{\circ} \mathrm{F}<F P\end{array}$

Dashes in the DOT Code column denote nonflammable vapors. Of the twenty-six Analytes, ten are extremely flammable and one is flammable, i.e., $42 \%$ are potential fire hazards, although this hazard is minimized in the open air where the concentrations cannot build up.

The explosion hazard potential is given by the Lower Explosive Limit (LEL) and the Upper Explosive Limit (UEL) which are the lowest and highest percentages of the chemical in air that, in the presence of a spark or flame, can cause explosive combustion. Known values ${ }^{10}$ are given in Table 6 (dashes indicate no data). The "hazard concern" column grades the danger as low, moderate (Mod.), or HIGH, where dashes indicate a nonexplosive vapor. Of course, the danger is often increased, sometimes dramatically, if highly reacting chemicals are present. Ozone is a special case in that it becomes extremely explosive if it crystallizes or is highly concentrated through chemical reactions. Of the twenty-six Analytes, methane, carbon monoxide, and 2-methyl-Pentane are particularly dangerous. However, all the explosive limits are so high that the danger in open air must be considered to be very low under most circumstances.

Sixteen Test Set Analytes are flammable and/or explosive hazards.

"The polychlorinated biphenyls and cyanide mixtures are included in Tables 6 and 7 because they do pose a danger. 


\subsection{Health Hazards}

Open air situations are primarily concerned with health effects. Each Test Set Analyte is categorized in Table 6 as a carcinogen, poison, or narcotic. It is also given a qualitative degree of toxicity. ${ }^{10}$ The chemical's carcinogenicity potential is denoted by "questionable (Q)" if there is minimal published evidence of possible carcinogenic activity, by "suspected (S)" if evidence is suggestive but not yet sufficient to constitute proof, and by "confirmed (C)" if it has been proven capable of causing cancer in humans. The poison or narcotic property is for the vapor form of the analyte. Technically, cyanide is not a poison but it forms the extremely poisonous $\mathrm{HCN}$ so quickly by so many different paths, that it is listed as a poison. Complete descriptions of the health effects and symptoms are given in reference 10 and references 14-17.

Twenty-Two Test Set Analytes are significant health hazards.

Table 6 - Hazardous properties of the Test Set Analytes.

\begin{tabular}{|c|c|c|c|c|c|c|c|c|}
\hline \multirow[b]{2}{*}{ Analyte } & \multicolumn{2}{|c|}{ Fire } & \multicolumn{3}{|c|}{ Explosion } & \multicolumn{3}{|c|}{ Health } \\
\hline & $\begin{array}{l}\mathbf{F P} \\
{ }^{\circ} \mathbf{F}\end{array}$ & $\begin{array}{l}\text { DOT } \\
\text { Code }\end{array}$ & $\begin{array}{c}\text { LEL } \\
\%\end{array}$ & $\underset{\%}{\text { UEL }}$ & $\begin{array}{c}\text { Hazard } \\
\text { Concern }\end{array}$ & $\begin{array}{c}\text { Carcin } \\
\text {-ogen }\end{array}$ & Toxicity & \begin{tabular}{|l} 
Poison/ \\
Narcotic
\end{tabular} \\
\hline Tributyl phosphate & 295 & --- & - & - & -- & -- & Mod. & --- \\
\hline Ammonia & -- & --- & 16.0 & 25.0 & Mod. & --- & -- & $\mathbf{P}$ \\
\hline 2-6-Di-tert-butyl-p-cresol & 260 & --- & -- & --- & --- & $\mathrm{Q}$ & Mod. & $\ldots$ \\
\hline Polychlorinated biphenyls & 383 & --- & -.- & --- & --- & $S$ & -- & $P$ \\
\hline Ozone & --- & --- & --- & --- & --- & $\mathrm{Q}$ & --- & $\mathbf{P}$ \\
\hline n-Butyl alcohol & 95 & $\mathrm{~F}$ & 1.4 & 11.2 & Mod. & --- & Mod. & $\ldots$ \\
\hline Cyanide & --- & --- & $\ldots$ & $\cdots$ & -- & ... & HIGH & $P$ \\
\hline Carbon dioxide & -.- & --- & -.. & -..- & -- & -.- & --. & -.- \\
\hline Carbon tetrachloride & --- & --- & --- & --- & -- & $\mathrm{S}$ & mild & $\mathbf{N}$ \\
\hline Butadiene & -105 & EF & 2.0 & 11.5 & Mod. & $\mathbf{S}$ & HIGH & -- \\
\hline Ethyl acetate & 24 & EF & 2.2 & 11.0 & Mod. & -.. & mild & $\mathbf{P}$ \\
\hline Acetonitrile & 42 & EF & 4.4 & 16.0 & Mod. & ... & Mod. & -- \\
\hline Nitrous oxide & -.. & --- & --- & --- & Mod. & --- & Mod. & --- \\
\hline Benzene & 12 & EF & 1.4 & 8.0 & low & $\mathbf{C}$ & Mod. & $\mathbf{P}$ \\
\hline Methylene chloride & --- & --- & 15.5 & 66.4 & low & $\mathbf{S}$ & mild & --- \\
\hline Carbon monoxide & 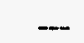 & --. & 12.5 & 74.2 & HIGH & -.- & mild & $\mathbf{P}$ \\
\hline Methyl ethyl ketone & 22 & EF & 1.8 & 11.5 & low & --- & Mod. & --- \\
\hline Biphenyl & 235 & -- & 0.6 & 5.8 & low & $Q$ & Mod. & --- \\
\hline Acetone & 0 & EF & 2.6 & 12.8 & Mod. & -.- & Mod. & _- \\
\hline 2-methyl-Pentane & 20 & EF & 1.0 & 7.0 & HIGH & --- & $\ldots$ & --- \\
\hline Trichlorofluoromethane & --- & --. & --- & ... & --- & --- & HIGH & --- \\
\hline Ethanol & 56 & EF & 3.3 & 19.0 & low & $\mathbf{C}$ & mild & --- \\
\hline Water & -.- & --- & -.. & --- & $\ldots$ & -.- & --- & -.- \\
\hline Methane & -369 & $\mathbf{E F}$ & 5.3 & 15.0 & HIGH & --- & ... & $\ldots$ \\
\hline Butyraldehyde & 20 & EF & 2.5 & 12.5 & low & --- & Mod. & --- \\
\hline Tridecane & --- & --- & --- & --- & -- & --- & Mod. & -- \\
\hline Dodecane & --- & --- & --- & --- & --- & $Q$ & --- & --- \\
\hline N-Nitrosodimethylamine & --- & --- & -- & ... & -.- & $\mathrm{s}$ & -.- & $\mathbf{P}$ \\
\hline
\end{tabular}




\subsection{Hazard Ratings}

Several measures of the danger from a chemical exist. One of the most-used measures is the Time-Weighted Average (TWA) noted above. Nearly all workers may be repeatedly exposed to the TWA value, day after day for a normal 8-hour workday and 40hour workweek, without adverse effect. Supplemental measures are the Short-Term Exposure Limit (STEL) and the Ceiling Limit (CL). Workers can experience for fifteen minutes the STEL value without adverse effects, provided the TWA is not exceeded. The CL concentration should never be exceeded. These measures for the Test Set Analytes are given in Table 7.,10 Tributyl phosphate and ammonia are the only Analytes with average tank headspace concentrations exceeding their TWA value. However, n-butyl alcohol and biphenyl Analytes plus the polychlorinated biphenyls and cyanide mixtures have maximum tank headspace concentrations which exceed their TWA value. In other words, six Analytes have had dangerous concentration levels measured within the tanks. However, the other Analytes cannot be ignored because they could become concentrated in the open atmosphere due to wind conditions or chemical reactions.

Table 7 - Hazard ratings of the Test Set Analytes.

\begin{tabular}{|c|c|c|c|c|c|c|}
\hline Analyte & \begin{tabular}{|c|} 
Average \\
ppm
\end{tabular} & $\begin{array}{c}\text { Average } \\
\text { HAR }\end{array}$ & $\begin{array}{l}\text { TWA } \\
\text { ppm }\end{array}$ & $\begin{array}{c}\text { STEL } \\
\text { ppm }\end{array}$ & $H R$ & $\boldsymbol{H A P}$ \\
\hline Tributyl phosphate & $2.96 \mathrm{E}-1$ & 13.600 & 0.2 & $\overline{---}$ & 3 & \\
\hline Ammonia & $2.23 E+2$ & 5.250 & 25 & 35 & 3 & \\
\hline 2,6-Di-tert-butyl-p-cresol & $3.27 \mathrm{E}-1$ & 2.490 & 1 & --- & 2 & \\
\hline Polychlorinated biphenyls & $4.50 E-6$ & 0.567 & $8 E-5$ & --- & 3 & -- \\
\hline Ozone & $2.70 \mathrm{E}-2$ & 0.447 & 0.1 & 0.1 & 3 & \\
\hline n-Butyl alcohol & $2.79 \mathrm{E}+0$ & 0.143 & 50 & 50 & 3 & \\
\hline Cyanide & $5.78 E-1$ & 0.104 & 5 & --. & 3 & $\cdots$ \\
\hline Carbon dioxide & $3.30 \mathrm{E}+2$ & 0.100 & 5000 & 30000 & 1 & \\
\hline Carbon tetrachloride & $5.16 \mathrm{E}-2$ & 0.055 & 5 & 10 & 3 & 1 \\
\hline Butadiene & $5.36 \mathrm{E}-2$ & 0.050 & 2 & 4.4 & 3 & 10 \\
\hline Ethyl acetate & $3.70 \mathrm{E}+0$ & 0.028 & 400 & --- & 3 & \\
\hline Acetonitrile & $5.71 \mathrm{E}-1$ & 0.020 & 40 & 60 & 3 & 10 \\
\hline Nitrous oxide & $3.20 \mathrm{E}-1$ & 0.010 & 50 & --- & 2 & \\
\hline Benzene & $3.59 \mathrm{E}-2$ & 0.010 & 10 & 32 & 3 & 10 \\
\hline Methylene chloride & $1.20 \mathrm{E}-1$ & 0.007 & 50 & 126 & 3 & 1 \\
\hline Carbon monoxide & $1.50 \mathrm{E}-1$ & 0.006 & 25 & 200 & 3 & \\
\hline Methyl ethyl ketone & $4.83 \mathrm{E}-1$ & 0.006 & 200 & 300 & 3 & 1 \\
\hline Biphenyl & $1.93 \mathrm{E}-4$ & 0.005 & 0.2 & -- & 3 & 1 \\
\hline Acetone & $9.40 \mathrm{E}-1$ & 0.003 & 750 & 1000 & 3 & \\
\hline 2-methyl-Pentane & $5.35 \mathrm{E}-1$ & 0.003 & 500 & 1000 & 3 & \\
\hline Trichlorofluoromethane & $2.06 \mathrm{E}-1$ & 0.001 & 1000 & 1000 & 2 & \\
\hline Ethanol & $4.69 \mathrm{E}-1$ & 0.001 & 1000 & -- & 3 & \\
\hline Water & $7.75 E+3$ & -- & -- & -- & 0 & \\
\hline Methane & $1.70 \mathrm{E}+0$ & --- & - & -- & 3 & \\
\hline Butyraldehyde & $1.46 \mathrm{E}+0$ & --- & --- & -- & 3 & \\
\hline Tridecane & $3.10 \mathrm{E}-1$ & --- & --. & $-\cdots$ & 2 & \\
\hline Dodecane & $2.26 \mathrm{E}-1$ & -. & --- & -- & 3 & \\
\hline N-Nitrosodimethylamine & $3.70 \mathrm{E}-2$ & $\ldots$ & -- & --- & 3 & 1 \\
\hline
\end{tabular}


The exact degree of danger posed by a chemical is scenario dependent: is the chemical inhaled or absorbed through the skin? Is it near an open flame? Can it pool in a low or enclosed location where it can reach explosive concentrations? However, it is useful to rank chemicals relative to each other based on their hazardous properties under normal atmospheric conditions. As noted before, a useful measure is the "Hazardous Atmosphere Rating (HAR)" which is the product of the concentration (in ppm) and the density (relative to air) divided by the TWA value (in $\mathrm{ppm}$ ). The $H A R$ values given in Table 7 indicate that tributyl phosphate, ammonia, and 2,6-Di-tert-butyl-p-cresol are particularly dangerous.

Table 7 includes two other hazard ratings. The Hazard Rating (HR) is a four number rating system which roughly identifies the level of the toxicity or hazard:
$H R=3 \quad$ The material is explosive, highly flammable, or highly reactive
$H R=2 \quad$ The material is flammable or reactive
$H R=1 \quad$ The material is combustible or presents some reactivity hazard
$H R=0 \quad$ The material is not dangerous

Not surprisingly, over $80 \%$ of the Analytes have HR values of 3, i.e., very dangerous. ${ }^{10}$

The other hazardous rating is based entirely on the chemical's toxicity and is restricted to the Environmental Protection Agency's list of Hazardous Air Pollutants (HAPs). This HAP weighting factor, the last column in Table 7, is a five number rating system which goes from 1 (least dangerous) to 100,000 (most dangerous) in multiples of 10. Of the ten HAPs included in Table 7, three are listed as fairly dangerous (HAP $=10)$, five are listed as slightly dangerous ( HAP $=1$ ) and two have not been assigned a weighting factor (---) ${ }^{14}$ Interesting enough, some of the most dangerous Toxic Air Pollutants are not classified as Hazardous Air Pollutants, probably due to their low concentrations in atmospheres normally encountered by the general population. 


\section{PRIMARY AND SECONDARY TEST SETS}

It is apparent from the hazardous ratings that not all of the twenty-six Analytes are dangerous in the concentrations which have been measured in the tank headspaces. In fact, the twenty-six Analytes can be divided into two Test Sets - a Primary Test Set which must be monitored and a Secondary Test Set which need not be monitored at this time. Furthermore, it is important to know for the operation of the TELA Monitor if the active or the passive subsystem will be able to measure the individual Analyte concentrations. This determination is obtained from a preliminary examination of the infrared spectrum of each Analyte.

\subsection{TEST SETS}

The twenty-six gas Analyte Test Set is reproduced in Table 8 but is divided into two segments: a twelve gas Primary Test Set and a fourteen gas Secondary Test Set.

In the Primary Test Set the first six Analytes are the atmospheric gases which could interfere with the measurements and/or occur at high concentrations within the tank headspaces. The next five Analytes are those pollutants with $H A R$ values above 1.0, i.e., the dangerous Analytes. They are ranked according to their maximum $H A R$ value. Although it has a low $H A R$ value, carbon tetrachloride is added to this set because it was, and still is, a commonly used solvent in above-ground work such as cleaning instruments. Consequently, tank headspaces are not the only source of this pollutant. These other sources could potentially increase its $H A R$ value considerably.

In the Secondary Test Set the first six Analytes are those that have HAP ratings. They are ranked by the HAP rating first and concentration second. The last eight are ranked by their $H R$ ranking first and concentration second. The HAR values are not used to rank these Analytes because they are all below the danger level, i.e., less than 1.0.

The Primary Test Set are those twelve Analytes which must be monitored because of their potential danger or interference effects. This Set includes the ammonia and tributyl phosphate Analytes. Because they occur in virtually all the tank headspaces and are easily detected, the presence at a high concentration of either Analyte is a good indication of a venting or leaking tank.

The Secondary Test Set are those fourteen Analytes which are not dangerous at presently known concentrations in the tank headspaces. They need not be monitored at this time. However, tank compositions are continually changing due to chemical reactions and these fourteen Analytes have the greatest potential for moving into the Primary Test Set. Furthermore, the first six Analytes are of interest to the Environmental Protection Agency. 
Table 8 - Detection method for prioritized Test Set Analytes.

\begin{tabular}{|c|c|c|c|}
\hline Analyte & $\begin{array}{c}\text { Detection } \\
\text { by Thermal } \\
\text { Emission } \\
\end{array}$ & $\begin{array}{c}\text { Detection } \\
\text { by Laser } \\
\text { Absorption }\end{array}$ & $\begin{array}{l}\text { Digital } \\
\text { Spectra } \\
\text { Chapter } \\
\end{array}$ \\
\hline \multicolumn{4}{|c|}{ PRIMARY TEST SET } \\
\hline Water & YES & YES & $\mathrm{E}$ \\
\hline Carbon dioxide & YES & YES & $\mathrm{F}$ \\
\hline Methane & YES & No & A \\
\hline Nitrous oxide & YES & No & $\mathbf{M}$ \\
\hline Carbon monoxide & YES & No & $\mathrm{F}$ \\
\hline Ozone & YES & YES & F \\
\hline Tributyl phosphate & YES & No & $\mathrm{T}$ \\
\hline Ammonia & YES & YES & $\mathrm{E}$ \\
\hline 2,6-Di-tert-butyl-p-cresol & YES & YES & - \\
\hline Biphenyl & YES & YES & -- \\
\hline n-Butyl alcohol & YES & YES & $\mathbf{J}$ \\
\hline Carbon tetrachloride & YES & No & $\mathbf{P}$ \\
\hline \multicolumn{4}{|c|}{ SECONDARY TEST SET } \\
\hline Acetonitrile & YES & YES & $\mathrm{N}$ \\
\hline Butadiene & YES & YES & A \\
\hline Benzene & YES & YES & $\mathrm{D}$ \\
\hline Methyl ethyl ketone & YES & YES & I \\
\hline Methylene chloride & YES & No & $P$ \\
\hline N-Nitrosodimethylamine & YES & YES & $\mathrm{N}$ \\
\hline Ethyl acetate & YES & YES & $\mathrm{K}$ \\
\hline Butyraldehyde & YES & YES & $\mathrm{H}$ \\
\hline Acetone & YES & No & I \\
\hline 2-methyl-Pentane & YES & No & $\mathrm{C}$ \\
\hline Ethanol & YES & YES & $\mathrm{J}$ \\
\hline Dodecane & YES & No & $\mathrm{C}$ \\
\hline Tridecane & YES & No & -- \\
\hline Trichlorofluoromethane & YES & No & $\mathbf{P}$ \\
\hline
\end{tabular}

\subsection{INFRARED SPECTRA}

Having obtained a list of Analytes, it is important to determine which Analytes will be detectable by the thermal emission and which Analytes will be detected by laser absorption, i.e., which subsystem of the TELA Monitor will be usable for each Analyte. The analysis presented here compares known Analyte spectra with the detection wavelengths of the TELA Monitor. In this first examination of the spectra, atmospheric interferences and system performance are not included.

The TELA Pollution Monitor uses a $\mathrm{CO}_{2}$ laser for atmospheric spectral absorption measurements in the $1090-926 \mathrm{~cm}^{-1}$ region and an acousto-optic tunable filter (AOTF) for 
atmospheric spectral emission measurements in the $5000-714 \mathrm{~cm}^{-1}$ region. From these wavelengths, Table 8 shows which Analytes have spectra within the AOTF detection range and which Analytes have spectra within the $\mathrm{CO}_{2}$ laser detection ranges of existing ${ }^{18,19} \mathrm{CO}_{2}$ lidar systems. For the known infrared spectra, we use the digitized spectra data base from Infrared Analysis, Inc. ${ }^{20}$ or the FTIR vapor phase spectra published by Aldrich, ${ }^{21}$ unless otherwise noted. The specific chapter, denoted by a capital letter, in the Infrared Analysis digitized data set is given in the last column. The digitized spectra are needed for real time analysis.

Barring atmospheric interferences, it would appear that:

The TELA Monitor can detect all 26 Analytes by thermal emission

The TELA Monitor can detect 15 Analytes by laser absorption

Furthermore, we already have 23 digitized spectra for these Analytes. 


\section{REFERENCES}

1. J. Osborn, TWRS Safety (Private Communication).

2. D. D. Mahlum, J. Y. Young, and R. E. Weller, "Toxicologic Evaluation of Analytes from Tank 241-C-103”, Report PNL-10189/UC-607 (1994).

3. J. L. Huckaby and M. S. Story, "Vapor Characterization of Tank 241-C-103", Report WHC-EP-0780 (1994).

4. C. H. Mulkey and K. D. Markillie, "Data Quality Objectives for Regulatory Requirements for Hazardous and Radioactive Air Emissions Sampling and Analysis", Report WHC-SD-WM-DQO-021 (1995).

5. L. H. Taylor and S. J. Mech, "Gaseous Analytes of Concern at Hanford Tank Farms," DOE Topical Report, Contract DE-AR21-95MC32087 (1996).

6. L. H. Taylor, D. R. Suhre, and S. J. Mech, "An Advanced Open-Path Atmospheric Monitor Design," Proc. 41st Annual Instrum. Soc. Am. Analysis Division Symposium, 155 (1996).

7. J. L. Huckaby, Pacific Northwest Laboratory (Private Communication).

8. P. H. Howard and M. Neal, Dictionary of Chemical Names and Synonyms, Lewis Publishers, Ann Arbor (1992).

9. Threshold Limit Values for Chemical Substances and Physical Agents and Biological Exposure Indices, American Conference of Governmental Industrial Hygienists, Cincinnati (1994).

10. R. J. Lewis, Sr., Hazardous Chemials Desk Reference, 3rd Ed., Van Nostrand Reinhold, New York (1993).

11. E. J. McCartney, Absorption and Emission by Atmospheric Gases, John Wiley \& Sons, New York (1983).

12. NASA, U.S. Standard Atmosphere, 1976, U.S. Government Printing Office, Washington, D.C. (1976).

13. G. P. Anderson, S. A. Clough, F. X. Kneizys, J. H. Chetwynd, and E. P. Shettle, "AFGL Atmospheric Constituent Profiles (0-120 km)," Air Force Geophysics Laboratory Report AFGL-TR-86-0110 (1986).

14. L. H. Keith and M. M. Walker, Handbook of Air Toxics, Lewis Publishers, New York (1995). 
15. R. J. Lewis, Sr., Sax's Dangerous Properties of Industrial Materials, Vol. II, Eighth Ed., Van Nostrand Reinhold, New York (1992).

16. M. Sittig, Handbook of Toxic and Hazardous Chemicals and Carcinogens, 3rd Ed., Noyes Publications, Park Ridge (1991).

17. The Merck Index: An Encyclopedia of Chemicals, Drugs, and Biologicals, 10th Ed., Mwindholz, S. Budavari, R. F. Blumetti, E. S. Otterbein, Eds., Merck \& Co.,Rahway (1983).

18. T. G. McRae and T. J. Kulp, "Remote Sensing of Fugitive Emissions Using the Backscatter/Absorption Gas Imaging Technique," Presented at 84th Annual A\&WMA Meeting (1991).

19. W. Diehl, P. Dinges, M. Fiedler, E. Golusda, R. Lange, and K. Luhmann, "Monitoring Air Pollutants with Compact and Mobile $\mathrm{CO}_{2}$-Laser Based Lidar," Presented at Optical Sensing for Environmental and Process Monitoring (1995).

20. P. L. Hanst and S. T. Hanst, Infrared Spectra for Quantitative Analysis of Gases, Infrared Analysis, Anaheim (1993).

21. C. J. Pouchert, The Aldrich Library of FT-IR Spectra, Ed. I, Vol. 3, Vapor Phase, Aldrich Chemical Company, Milwaukee (1989). 
Report Number (14) DOE/mc/32087--5633

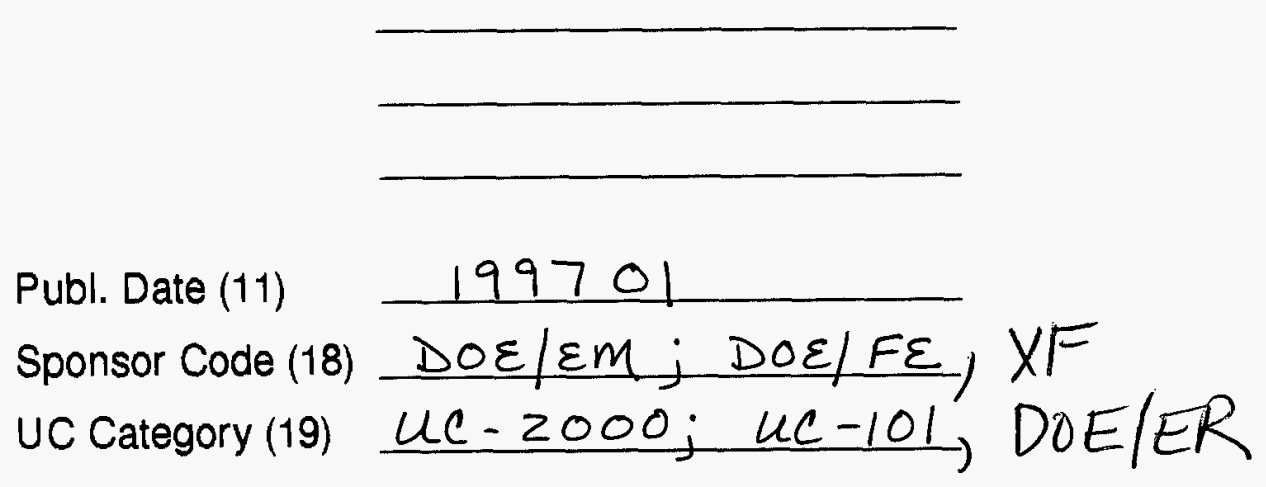

